\title{
Double the Units: How Increasing the Number of Advertisements while Keeping the Overall Duration of Commercial Breaks Constant Affects Radio Listeners
}

\begin{abstract}
Robert F. Potter
Recently, a major radio station ownership group pressured the advertising industry to transition the accepted unit of advertising from the 60-second commercial to 30-second spots. This transition shows signs of being successful, and it is now possible for stations to play twice as many individual ad units while keeping the overall duration of commercial breaks constant. This withinsubjects experiment tests the effects of such a circumstance on variables including listener cognitive effort, arousal, attitudes, and memory. Results suggest that breaks with more ad units lead to cognitive disengagement, increased duration estimates for the ad breaks, and more negative attitudes compared to ad breaks with fewer units.
\end{abstract}

All commercial media outlets face the common frustration of having essentially two groups of customers that they must keep happy. The first group is the audience itself. Television programmers select shows they feel are the most entertaining and the most likely to attract a large viewer base. Newspapers and magazines include stories and create entire sections on the hope of establishing a connection with a larger readership. Commercial radio outlets also exist to please the listening audience. Format decisions (i.e., "should we be a Country station, or a Top 40

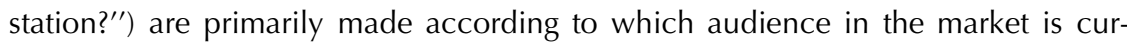
rently underserved (Newton, 2002). Even at stations with established music formats, satisfying the listeners continues to influence decisions surrounding individual songs to put in the rotation (Ahlkvist, 2001).

Audience satisfaction is not the only concern for commercial radio programmers. In fact, many argue that the aggregation of large audiences is merely a means to

Robert F. Potter (Ph.D., Indiana University) is an Associate Professor and Director of the Institute for Communication Research in the Department of Telecommunications at Indiana University, Bloomington. His research explores the cognitive processing of media messages-particularly the impact of audio on cognition and emotion.

The author thanks Brian Wilson and Ashley Sanders-Jackson for their assistance in data collection and Pete Jensen for his help in stimuli creation. 
an end in order to attract the second customer base-individual advertisers and/or the advertising agencies representing them (Webster \& Phalen, 1997). Advertising agencies place their clients on stations that attract the greatest number of listeners within particular target demographics and psychographics. A radio station essentially sells that audience to those agencies. It is precisely this advertiser base that, through the allocation of marketing budgets, provides the capital necessary for the broadcast station to remain viable and on the air. Advertisers' only interest in the station, however, is as a source of a large (and hopefully loyal) listenership to be exposed to their marketing message during commercial breaks. If the size of the audience is large enough, the station should have little trouble in finding advertisers to purchase the set number of commercial units the station schedules per hour. If the size of the audience is small, however, the station may find it difficult to convince advertisers to include it as a worthwhile part of a marketing plan.

It is rare indeed for radio listeners to say that they tune to a station in order to hear the commercials that it plays. In fact, listeners are more likely to tune out during commercial breaks (Elliot \& Speck, 1998). What they tune in for is the music or talk show that provides entertainment and/or pertinent information to their lives. If the station can maximize this sense of programming functionality, and do so better than competitors in the market, audience size should grow. With that growth the attractiveness of that station to advertisers will also increase.

This is where a delicate and difficult balance must be struck by radio station programmers who, unlike local television programmers (Affe, 2005), have both some flexibility and the authority to determine how many commercials are played per hour, and when they occur. Although individual local radio programmers used to be much more autonomous in their decision-making, ownership consolidation resulted in larger group-ownership situations where programming decisions are made more centrally, often by regional programmers responsible for commonly owned stations across formats. Such was the case in July 2004, when Clear Channel Communications announced a change in their corporate formatting strategy. The strategy, dubbed "Less is More," was an attempt to reduce the audience's perception of commercial clutter by making three changes. The first was an overall decrease in the number of commercial minutes per hour, a more traditional definition of commercial clutter (Ha, 1996). Secondly, Clear Channel decreased the number of commercial breaks per hour on their stations, essentially limiting the number of times the entertainment or information programming was interrupted. Academic researchers studied this strategic change and its impact on perceptions of clutter, with mixed results (Potter, Callison, Chambers, Chung, \& Lee, 2005; Potter, Callison, Chambers, Edison, \& Potter, 2008). The final portion of the "Less is More" initiative attempted to reduce perceptions of clutter by forcing radio producers to be briefer in their creative constructions-communicating the unique selling proposition of their client in only 30 seconds. Traditionally, an overwhelming percentage of radio advertising consisted of 60-second commercials. Understandably therefore, there was tremendous reluctance to this announcement by advertising creatives. Still, 
Clear Channel went on record as saying that they plan to transition the radio industry toward primarily using 30-second commercials. Clear Channel suggests that this new format is better for both listeners and ad agencies because listeners get more of what they want and it will create an environment promoting more competition in the marketplace.

The radio industry may be accepting this insistence on shorter commercial units (Media Monitors, 2007). If Clear Channel successfully transitions the industry from dependence on 60-second commercials toward the use of shorter ads, managers may attempt to increase overall revenue by keeping the duration of each advertising break consistent but filling that time with twice as many 30-second ads as they did 60-second ads in the past. Some may correctly argue this is contrary to Clear Channel's original "Less is More" strategy, which instead calls for initial reductions in the number of commercials per hour and higher than traditional prices for the shorter units (Allan, 2007). Nevertheless, Clear Channel is not the only radio group with pressures to generate short-term profits. In other words, other general managers and sales managers may be tempted to double the number of commercial units while keeping the overall duration of their advertising breaks consistent. This study investigates the effects of such a decision on listener perceptions of advertising clutter and engagement to persuasive messages in the commercial breaks.

\section{Theoretical Approach and Hypotheses}

This study is primarily guided by Lang's Limited Capacity Model of Motivated Mediated Message Processing (LC4MP) (Lang, 2006), which conceptualizes human beings as information processors whose cognitive system consists of a limited resource pool, the content of which is allocated simultaneously and dynamically across three subprocesses. The encoding subprocess is the gateway to cognition, essentially moving information from the sensory store to what often has been referred to as short-term memory. The retrieval subprocess activates memory networks in long-term memory, making information within them available for manipulation by the short term memory system. Within LC4MP, the task of processing a media message, such as a radio commercial, is described as encoding information from the message while simultaneously retrieving information stored in long-term semantic memory networks. This retrieval makes sense of the message being processed, and makes subsequent memory network linkages between previously encoded knowledge and new information. If this new information is then deemed relevant to the individual (either due to their interests, or motivationally relevant to the listener as a biological organism), the storage subprocess transfers the new associations into long-term memory networks.

According to the model, encoding details of a radio message occurs through the interplay of top-down and bottom-up cognitive processes. People are perhaps more intuitively aware of the top-down influence; while driving to work one may have 
a need to hear the traffic report, or one may be in the market for a new sofa and therefore more aware of commercials announcing a big sale at the local furniture store, etc. However, encoding can also come about as an automatic response to structural features of the message itself, regardless of content, through the orienting response (OR). The OR is a biological mechanism that responds to learned signals or changes in the immediate environment (Ohman, 1979). Using a precursor to the LC4MP as a theoretical guide, Potter and colleagues demonstrated that structural changes within auditory messages provided the requisite environmental change to elicit an OR which resulted in automatic encoding of information in the first few moments following the structural onset (Potter, Lang, \& Bolls, 2008). Furthermore, this elicitation occurred in both radio listeners who paid close attention to the message and those who merely had the radio playing in the background (Potter, Lang, \& Bolls, 1998). The structural features identified in this work included changes in announcers, sound effects, production effects such as laser sounds and echo, music onsets, and commercial onsets.

These findings can help make predictions about the specific situation under investigation in this study. Consider, for example, a 5-minute commercial break. Traditionally, this time conceivably would be filled with five, 60 -second commercials. The same total duration could also be obtained by airing 10, 30-second messages. Doubling the number of units doubles the number of commercial onsets, and the number of times that the listener's cognitive system automatically encodes information as a result of orienting to them. Initially, this may benefit the task of processing sequential persuasive messages. Automatic orienting brings the listeners back to the task of processing the message, and because the message is new, they spend at least a brief amount of time processing it in order to make sense of it. Therefore, it is expected that in the early portion of a commercial break, having more, and shorter commercials will increase cognitive effort spent on the processing of the advertising break. However, it also follows that each time a listener orients to the onset of a new commercial (recognized through the presence of an entirely new announcer, perhaps new music, and new semantic content) it increases an awareness of how many sequential commercials to which they were exposed. As awareness that the number of sequential commercials is increasing and reaching a total that is quite high, media users may become more likely to tune out. If the physical ability to tune out is not available, listeners may mentally disengage from processing the persuasive messages. Although orienting to structure will still occur (in fact, by definition, cannot be suppressed), controlled processing of information following the structural onset is predicted to be actively avoided. If this is the case, it is expected that in a condition where the number of commercial onsets is doubled, listener disengagement occurring later in the commercial break will result in decreased cognitive effort applied to the processing of the advertising break. Therefore, the first hypothesis asserts that:

$\mathrm{H}_{1}$ : There will be a number of units by time interaction on cognitive effort. Early in the 5-minute commercial break, subjects listening to the station playing 
10 units will show greater cognitive effort than subjects listening to the station playing five units. This effect will diminish over time, however, as subjects disengage from the 10-unit station.

It is assumed that listeners will keep some sort of internal tally of the number of sequential commercials to which they are exposed. By design, that tally will increase more rapidly in the 30-second condition. It is predicted that, along with cognitive disengagement will come negative affect and higher arousal as listeners become annoyed with the station with double the number of units as it plays more and more individual commercials. Therefore,

$\mathrm{H}_{2}$ : There will be a number of units by time interaction on negative affect such that listeners will have greater negative response as time goes on during the station playing 10, 30-second units, while negative affect will remain comparatively constant for the station playing 5, 60-second units.

Because experimental participants typically exhibit a substantial decrease in autonomic arousal levels in the research laboratory as they become more accustomed to the procedures and their surroundings, an absolute increase in arousal is not predicted for the doubled-units condition. Nevertheless, a prediction is made for an interaction in relative arousal decrease across the number-of-units conditions:

$\mathrm{H}_{3}$ : There will be a number of units by time interaction on autonomic arousal such that listeners will have less skin conductance level decrease over time when exposed to the station playing 10, 30-second units compared to the station playing 5, 60-second units.

It is expected that the physiological reactions predicted in the first three hypotheses also will manifest themselves in attitudes toward the stations playing the commercials. Psychological research in the area of time estimation showed that increasing the number of discrete units in a set duration led to an increase in subsequent retrospective evaluations of the length of time passed (Predebon, 1996; Tse, Intriligator, Rivest, \& Cavanaugh, 2004). Although most of this work is in the area of cognitive science and focused in the time domain of milliseconds, it is possible that it may also be generalized to longer durations. If a commercial for a specific product is viewed as an individual unit, such a generalization is represented in the following hypothesis:

$\mathrm{H}_{4}$ : There will be a main effect of number of units on time estimation for the commercial break, with the station playing 10, 30-second ads receiving higher estimations than the station playing 5,60-second ads.

Previous research on advertising clutter revealed negative appraisals are expected toward media outlets perceived to be more cluttered (Elliot \& Speck, 1998). Because 
the prediction made in $\mathrm{H}_{4}$ and the combination of those made in $\mathrm{H}_{1}$ through $\mathrm{H}_{3}$ both indicate an increase in perceived clutter during exposure to the ad break with double the number of units:

$\mathrm{H}_{5}$ : There will be more negative attitudes toward 5-minute ad breaks containing 10 units than those containing 5 units.

\section{Method}

\section{Design}

In order to test these hypotheses, a mixed 2 (Number of Units) $\times 4$ (Order of Presentation) factorial-design experiment was conducted. Number of Units was a within-subjects factor, with two levels representing whether the 5-mintue commercial break was comprised of 10, 30-second commercials, or 5, 60-second commercials. Each participant was exposed to each level of this factor, using different stations as media vehicles to deliver the manipulation. Order of presentation was a between-subjects variable representing the four systematic presentation orders designed to decrease the likelihood that the effects found were due to order of music or commercial presentation of the station.

\section{Participants}

Forty-seven ( $N=47$ ) telecommunications undergraduate students from a large Midwestern university were given course credit for their participation. All provided informed consent according to approved protocols by the university's Institutional Review Board. Eighteen males (38.3\%) and 29 females (61.7\%) participated, with none withdrawing.

\section{Stimulus Materials}

The stimuli consisted of sample segments from two supposedly actual radio stations that had contracted a research institute to obtain listener responses to their programming. Each segment was about 20 minutes in length and took the following general format: each opened with a station identification sounder, followed by two songs, then another station sounder, 5 minutes of commercials, a third station sounder, two songs, and a final station sounder.

Songs used in the stimuli were selected by a pretest conducted by a different set of participants. Pretest participants were asked to rate 24 Top-40 song clips in terms of arousal, valence, liking, and how tired they were of the song. In total, 
eight songs were selected for the current experiment. Songs were chosen by subtracting the burn-out scores from the liking scores, with the highest values chosen while attempting to mimic actual music rotations on Top-40 stations taking into consideration valence, arousal, and tempo.

Ten target, 60-second advertisements, and five, 30-second filler advertisements, were collected from out-of-town radio markets in order to reduce familiarity. Ads were selected promoting products within categories of interest to the age demographic of the experimental subjects (i.e., beer, pizza restaurants, sports cars, dance clubs, etc.). Each target ad was originally 60-seconds in duration. Research associates with professional audio editing experience used a digital editing program to create 30-second versions of all the target ads. Care was taken in this process to ensure that as little product information was removed from the original commercial as possible.

The Number of Units manipulation was achieved in each within-subjects condition by selecting five of the 60 -second target ads to comprise the five-unit station condition. The edited 30-second versions of the other five target ads were then randomly ordered along with the five filler ads in the commercial break of the other station-thereby creating the 10, 30-second ads condition. Each participant heard each product advertisement only once. No orders contained both a 30- and 60 -second advertisement for the same product.

Two orders began with the five-unit station, the other two with the ten-unit station. Station identification was chosen from outside the local market, and also varied, so that neither station moniker ("Power 95" and "The River") was associated with a particular level of the number-of-units factor.

\section{Apparatus}

This experiment was controlled using MediaLab software (Jarvis, 2004) running on a Pentium IV computer with Windows XP installed. MediaLab was also used to collect self-reported attitude data. Physiology data were collected using a Coulbourn Lablink V system and the VPM software package (Cook, 1999). Subjects listened to the radio station stimuli through headphones, with the volume determined and kept constant by the experimenter.

\section{Dependent Measures}

Cognitive Effort. Heart rate is recognized as an indication of cognitive effort (Lang, Potter, \& Bolls, 2009). Slower heart rate indicates greater cognitive effort being paid to a media message. In this study, heart rate data were collected using $3 \mathrm{AG} / \mathrm{AGCL}$ electrodes filled with conductive gel; two of which were attached to the participant's forearms and the third (acting as a ground) on the non-dominant arm (Stern, Ray, \& Quigley, 2001). Heart rate was calculated as inter-beat intervals (IBIs) recorded in milliseconds. 
Arousal. Skin conductance level provided an operational definition of physiological arousal during the commercial break (Lang et al., 2009). Data were collected using 2 AG/AGCL electrodes filled with neutral gel. These were placed on the palm of the participant's non-dominant hand after it was hydrated with distilled water. The skin conductance signal was sampled at a rate of 20 times per second and later output offline every second.

Negative Affect. The corrugator supercilli muscle group lies just above the eyebrow in humans (Tassinary \& Cacioppo, 2000). Activation of the muscle group is identified as a psychophysiological correlate of negative affect (Bradley \& Lang, 2000; Cacioppo, Berntson, Larsen, Poehlmann, \& Ito, 2000). Several studies have validated the use of corrugator EMG to provide real-time assessment of negative affect in response to mediated messages (Bolls, Lang, \& Potter, 2001; Hazlett \& Hazlett, 1999; Potter, LaTour, Braun-LaTour, \& Reichert, 2006). In this study, corrugator EMG data were collected by placing two small AG/AGCL electrodes over the corrugator muscle group above the subject's left eyebrow, after cleaning and slightly abrading the area with a cotton pad containing pumice and saturated with isopropyl alcohol. Signals were sampled 20 times per second, sent to a bioamplifier and smoothed, using a contour integrator set at $800 \mathrm{~ms}$. They were later output as 1 -second averages offline.

Advertising Attitudes. Participants were asked a series of 7-point Likert scale items pertaining to how they felt about advertisements and commercial breaks in general. They reported how much they agreed with the statement presented on a computer screen. An example of these questions is: "When a radio station goes to a commercial, the commercial break disrupts my listening experience." After both the 10-unit and 5-unit stimuli segments, they were asked identical questions about the stimulus they were just exposed to.

\section{Procedure}

Upon arrival, each participant signed an informed consent form. They were informed that the research would consist of them listening to two separate radio stations and providing their feedback on each. Next the electrodes that measured physiology variables were applied. After ensuring that the subject was comfortable, and addressing any questions, the subject put headphones on, and the experimenter left the room.

The subject first answered a set of questions focused on demographics, radio listening, and general advertising attitude items. When finished with these, the subject listened to the first radio segment, while seated comfortably for a session that lasted about 20 minutes. After the segment, they completed a questionnaire containing items referring to their attitudes toward the station they had just heard, including the attitude questions focusing on the commercial break. 
After attitude data were collected for the first station, the researcher reentered the room and explained that the subject would now listen to a second station-one that was unrelated to the first and even broadcast in an entirely different city-and that they would be asked their attitudes and opinions toward it afterwards as well. The second radio segment was played and followed by the same attitude questionnaire.

When finished with the final station questionnaire, the electrodes were removed and the subjects were thanked for their participation and dismissed.

\section{Data Cleaning, Preparation and Analyses}

IBIs in the heart rate data were cleaned and converted to heart rate in beats per minute (bpm) for each second using an algorithm from Cook (1999). For all physiological dependent variables, 299 change scores were calculated by subtracting the measure during the first second of the commercial break from each subsequent second. These change scores were then aggregated into 59, 5-second segments, with the last 4 seconds not being used in analysis due to the inequality of segment duration. Experimenter or apparatus error occasionally prevented psychophysiological data from being properly collected. As a result, final number of subjects varied across dependent variable: self-report $(N=47)$, heart rate $(N=42)$, skin conductance $(N=43)$, and corrugator EMG $(N=36)$.

Attitude items were coded so that a higher score indicated a more favorable attitude toward the commercial break. Factor analyses were completed for the index administered after each station segment. Both had high Cronbach's alpha values $\left(\alpha_{5 \text {-unit }}=.922 ; \alpha_{10 \text {-unit }}=.921\right)$, and values were therefore collapsed prior to analysis.

The impact of the Order of Presentation between-subjects factor was not statistically significant in any analysis, and has been removed from all statistics reported below.

\section{Results}

\section{Doubling the Units and Cognitive Effort}

The first hypothesis predicted that listeners would initially allocate more cognitive effort processing ads in the 10-unit break compared to those in the 5-unit break. However, it was also hypothesized that this effect would interact with time, and eventually listeners would disengage from processing the 10-unit break. Operationally, change in cardiac activity over time was used as a physiological correlate of cognitive effort. This hypothesis was statistically tested using a 2 (Number of Units) $\times 59$ (Time in 5-second increments) repeated-measure ANOVA. Results show a significant main effect for Number of Units $\left(F(1,58)=4.874, p<.033, \mathrm{Eta}^{2}=\right.$ 


\section{Figure 1}

\section{Number of Units $\times$ Time Interaction on Cardiac Change Scores}

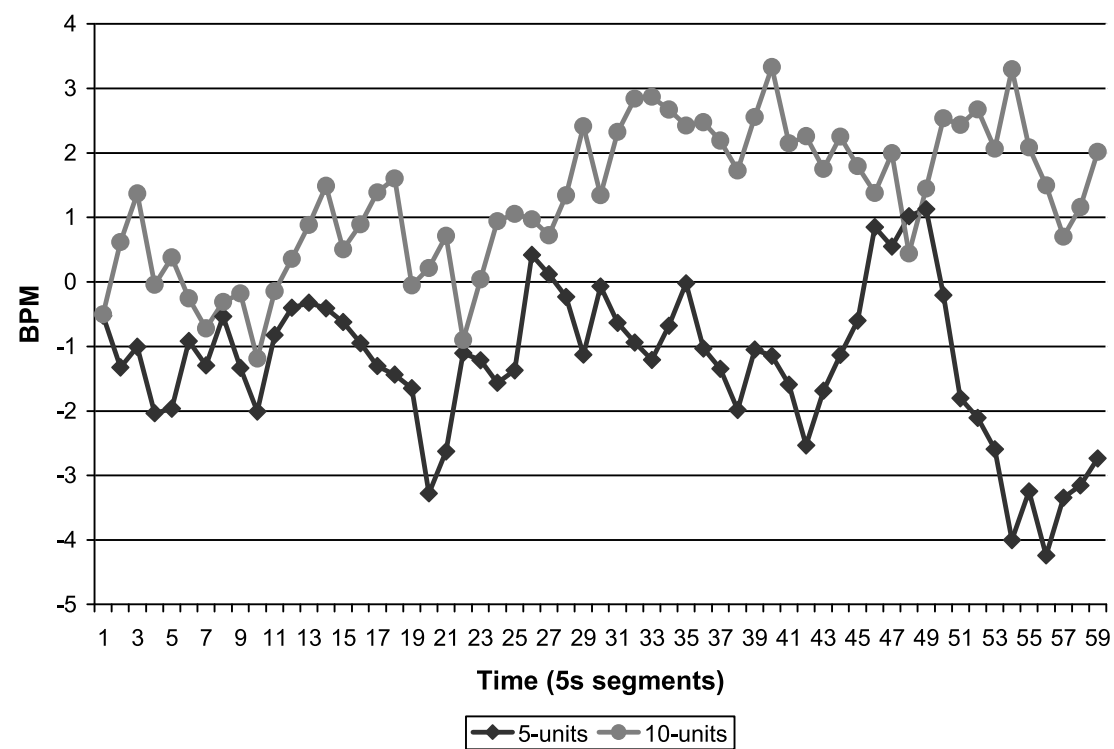

$.106)$, and a significant Number of Units $\times$ Time interaction $(F(58,2378)=2.424$, $\left.\mathrm{p}<.001, \mathrm{Eta}^{2}=.056\right)$.

The interaction can be seen in Figure 1. As predicted, there is clear disengagement occurring during the 10-unit condition with heart rate trends steadily increasingsuggesting less attention being paid to the ad break-from approximately time segment 22 (111 seconds into the ad break). Meanwhile, cardiac activity diverges in the 5-unit condition, showing cardiac activity almost entirely below baseline levels suggesting cognitive engagement throughout the course of the commercial break. For this reason, $\mathrm{H}_{1}$ is only partially supported; although there was disengagement from the 10-unit station, there was not the initial increase predicted to occur in response to more frequent commercial onsets.

\section{Doubling the Units and Negative Affect}

It was predicted that increasing the number of units twofold would result in greater negative affect even if the overall duration of the commercial break was held constant. Expectations were for a significant Number of Units $\times$ Time interaction on the corrugator change scores from baseline. Statistical results show no significant main effects or interactions ( $F$-values $<1) . \mathrm{H}_{2}$ is rejected. 
Figure 2

Number of Units $x$ Time on Skin Conductance Level Change Scores

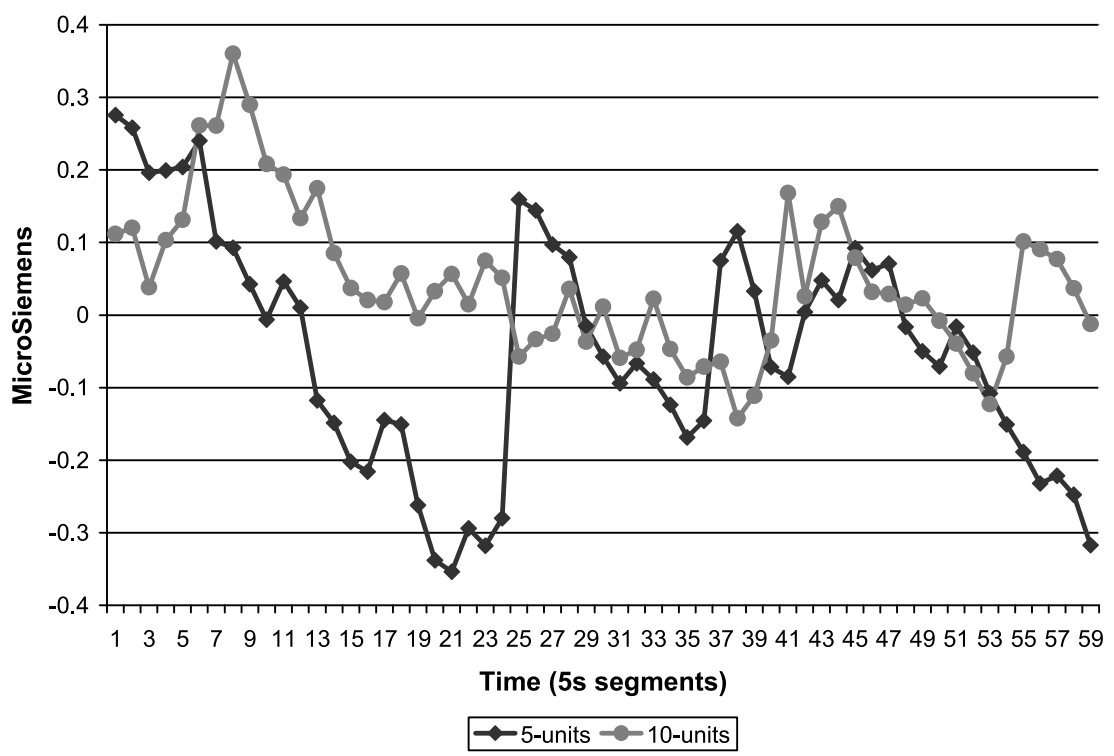

\section{Doubling the Units and Autonomic Arousal}

Becoming comfortable during experimental procedures usually results in a marked decrease in skin conductance levels over the course of time within the media laboratory. It was predicted that the comparatively rapid succession of orienting responses to commercial onsets expected to occur in response to the 10-unit station, along with an awareness that the overall number of commercials they were being exposed to was rapidly increasing, would prevent subjects from experiencing such arousal decrease while listening to those stations compared to when listening to the 5-unit station. This hypothesis was also tested using a 2 (Number of Units) $\times$ 59 (Time in 5-second increments) repeated-measures ANOVA. This resulted in a non-significant main effect and interaction. However, after visual inspection of the change scores (see Figure 2), a subsequent analysis was conducted for time segments 7 through 24. This returned a main effect of Number of Units that approached marginal significance $(F(1,42)=2.680, p=.11)$, with the expected pattern of a less marked decrease in arousal occurring during processing of the 10-unit station.

\section{Effect of Doubling the Units on Time Estimation}

$\mathrm{H}_{4}$ predicted a main effect of number of units on time estimation, with subjects approximating the duration of commercial breaks with 10 units as longer than those 
containing 5 units. There was a significant main effect of Number of Units on time estimation $\left(F(1,46)=20.271, p<.001, \mathrm{Eta}^{2}=.306\right)$. Breaks with 10 units were estimated to be an average of 277.28 seconds $(S D=19.24)$ compared to only 229.57 seconds $(S D=13.61)$ for breaks containing 5 units. This hypothesis is supported.

\section{Doubling the Units and Attitudes}

After the presentation of each radio segment, participants completed a 10-item index measuring their attitudes toward the commercial break to which they were just exposed. Each item asked how much they agreed with a statement on the screen. Examples of these statements are, "The commercial break I just heard was irritating," and "The commercial break I just heard made me want to change the station." $\mathrm{H}_{5}$ predicted more negative attitudes toward the 10-unit ad break than the 5 -unit break. Analysis returned a significant main effect $(F(1,46)=20.271, p<$ $\left..001, \mathrm{Eta}^{2}=.195\right)$. In support of this hypothesis, 5 -unit commercials were judged more favorably $(M=3.211, S D=.183)$ than their 10 -unit counterparts $(M=2.685$, $S D=.184)$. This hypothesis is supported.

\section{Discussion}

This study used the theoretical underpinnings of a cognitive model of mediated message processing (Lang, 2006) and work in the psychology of time estimation (Predebon, 1996; Tse et al., 2004) as tools to investigate possible listener reactions to a recent phenomenon within the radio industry. As part of its "Less is More" campaign designed to decrease listener perception of advertising clutter, Clear Channel Communications is trying to change the standard advertising vehicle from the 60 second commercial announcement to the 30-second announcement. They have, in fact, even sold 15-second "ad-lets" and 5-second "blips" to clients interested in primarily raising brand awareness among the listening audience. While the strategy of Clear Channel is to reduce the hourly number of units on stations they own, if they are able to transition the industry into accepting shorter individual units, competing stations may be tempted to keep the overall duration of commercial breaks constant while dividing them into ever-finer discrete units. Results from the current experiment suggest that doing so may backfire and lead to detrimental results for both the station and its advertisers.

Results show that keeping the commercial break itself at 5 minutes but filling that time with 10 commercials resulted in subjects self-reporting longer estimates of time devoted to advertising compared to when that time was filled with five commercials. Furthermore, attitudes toward the commercial break were more negative when twice the number of commercial units occurred. Stations interested in increasing their bottom-line by migrating entirely to 30 -second commercials 
without making an adjustment in overall commercial break durations should move cautiously as the increased revenue is likely to be offset by negative feelings among listening audiences. As mentioned in the beginning of this article, advertisers are only interested in stations to the extent that they deliver a large and loyal listening audience of particular demographic and psychographic composition. The offshoot of the migration to shorter units may in fact be increased perceptions of clutter on stations, if these shorter units are scheduled without a subsequent decrease in the overall duration of the ad break itself. Exactly what the overall duration trade-off must be if stations are to expect no negative listener perceptions after migrating to a shorter unit is a question left for future research.

Physiological data in the current study also provide reason for advertisers to be skeptical about the move to shorter individual ad units unless they also take an active role in scheduling where in the break their messages appear. Based upon previous work identifying auditory structural features that cause orienting responses (Potter et al., 2008) it was expected that the onset of each new commercial would result in momentary automatic encoding of the beginning of the new message. Coupling this with the work of Tse et al. (2004) it was expected that on the 10unit stations where commercial onsets occurred more frequently, listeners would become increasingly aware of the cluttered nature of the break and, eventually, cognitively disengage from processing. According to the cardiac data in Figure 1, this occurred at approximately 110 seconds, after which heart rate levels began a steady positive trend indicative of less cognitive effort being paid. After this point in time-for more than half of the presentation period-listeners' heart rates were above baseline levels. Cardiac response to the same 5-minute period containing 5 units resulted in cardiac levels below baseline throughout the commercial break. In fact, subjects were cognitively engaged more than $90 \%$ of the time in the ad breaks containing 60-second commercials, based on change from baseline.

Interestingly, it is also during the early part of the ad break, just prior to when cardiac data shows disengagement from processing the 10-unit stations, when listeners showed a difference in arousal responses between the two conditions. Perhaps the greater arousal experienced during the station playing more units was in result to a feeling of agitation with the sense that the break was overly cluttered. Although corrugator data did not support this explanation, it is something that future studies should continue to explore not only using physiological measures, but also other real-time measures like continuous response (Biocca, David, \& West, 1994). Researchers may want to design studies that allow participants the ability to change radio stations during advertising breaks as a way of identifying behavioral effects beyond the psychophysiological results reported here.

These results also provide further support for the claim by Allan (2007) that advertisers who begin utilizing 30-second commercials in their radio marketing plans should, to as much extent possible, negotiate for placement of these messages early in commercial breaks. While Allan presented memory data to support the primacy effect in an advertising pod, the current physiological data show that after approximately 110 seconds listeners become cognitively disengaged. 
Beyond offering practical recommendations, results from this study add to the theoretical literature by continuing to enrich the conceptualization of commercial clutter. While past work showed the impact of operationalizing clutter as the frequency with which entertainment content is interrupted (Potter et al., 2008) this study demonstrates that even within a single commercial pod, both listener attitudes and online cognitive processing are impacted by how finely-grained individual messages are divided. Furthermore, the support of the current set of hypotheses seems to suggest that results from perceptual studies exploring increases in the number of discrete units of extremely short duration (e.g., Tse et al., 2004) may be able to cross levels of analysis to make predictions about longer durations such as commercial breaks. Future research should continue to investigate the variables affecting perceptions of clutter, including duration of individual units as well as the structural and content complexity of those units.

\section{References}

Affe, R. B. (2005). Television station programming strategies. In S. Eastman \& D. A. Ferguson (Eds.), Media programming (pp. 187-215). Belmont: Wadsworth.

Ahlkvist, J. A. (2001). Programming philosophies and the rationalization of music radio. Media, Culture, \& Society, 23(3), 339-358.

Allan, D. (2007). Comparative effectiveness of 30- versus 60 -second radio commercials on recall and rate. Journal of Radio Studies, 14(2), 165-177.

Biocca, F., David, P., \& West, M. (1994). Continuous response measurement (CRM): A computerized tool for research on the cognitive processing of media messages. In A. Lang (Ed.) Measuring psychological responses to media messages (pp. 15-65). Mahwah, NJ: Lawrence Erlbaum Associates.

Bolls, P. D., Lang, A., \& Potter, R. F. (2001). The effects of message valence and listener arousal on attention, memory, and facial muscular responses to radio advertisements. Communication Research, 28(5), 627-651.

Bradley, M. M., \& Lang, P. J. (2000). Measuring emotion: Behavior, feeling, and physiology. In R. D. Lane \& L. Nadel (Eds.), Cognitive neuroscience of emotion (pp. 242-276). New York: Oxford University Press.

Cacioppo, J. T., Berntson, G. G., Larsen, J. T., Poehlmann, K. M., \& Ito, T. A. (2000). The psychophysiology of emotion. In M. Lewis \& J. M. Haviland-Jones (Eds.), Handbook of emotion (pp. 173-192). New York: The Guilford Press.

Cook, E. W. (1999). VPM (Version 11.0). Birmingham, AL.

Elliott, M. T., \& Speck, P. S. (1998). Consumer perceptions of advertising clutter and its impact across various media. Journal of Advertising Research, 38(January/February), 29-41.

Ha, L. (1996). Observations: Advertising clutter in consumer magazines: Dimensions and effects. Journal of Advertising Research, 36(4), 76-84.

Hazlett, R. L., \& Hazlett, S. Y. (1999). Emotional response to television commercials: Facial EMG vs. self-report. Journal of Advertising Research, 39(2), 7-23.

Jarvis, B. (2004). MediaLab (Version 2004.2.1). New York, NY: Empirisoft.

Lang, A. (2006). Using the limited capacity model of motivated mediated message processing to design effective cancer communication messages. Journal of Communication, 56(s1), S57-S80.

Lang, A., Potter, R. F., \& Bolls, P. D. (2009). Where psychophysiology meets the media: Taking the effects out of media research. Media effects: Advances in theory and research. J. Bryant and M. B. Oliver. New York, Routledge: 185-206. 
Media Monitors: Salem, Clear Channel, Cox running fewest commercials per hour. (2007). Retrieved February 24, 2008, from http://www.fmqb.com/article.asp?t=p\&id=439021.

Newton, G. D. (2002). Music radio programming. In S. T. Eastman \& D. A. Ferguson (Eds.), Broadcast/cable/web programming. (pp. 351-392). Belmont, CA: Wadsworth/Thomson Learning.

Ohman, A. (1979). The orienting response, attention, and learning: An information-processing perspective. In H. D. Kimmel, E. H. Van Olst \& J. F. Orlebeke (Eds.), The orienting reflex in humans (pp. 443-471). Hillsdale, NJ: Lawrence Erlbaum Associates.

Potter, R. F., Callison, C., Chambers, T., Chung, Y., \& Lee, S. (2005, May). Effects of commercial pod frequency on attitudes, emotional response, attention and memory in radio listeners across two demographic age groups. Presented to the International Communications Association at their annual conference in New York, NY.

Potter, R. F., Callison, C., Chambers, T., \& Edison, A. (2008). Radio's clutter conundrum: Better memory for ads, worse attitudes toward stations. International Journal of Media Management (10), 139-147.

Potter, R. F., Lang, A., \& Bolls, P. D. (1998). Orienting to structural features in auditory media messages. Psychophysiology, 35(Supplement), S66.

Potter, R. F., Lang, A., \& Bolls, P. D. (2008). Identifying structural features of audio: Orienting responses during radio messages and their impact on recognition. Journal of Media Psychology: Theories, Methods, and Applications, 20(4), 168-177.

Potter, R. F., LaTour, M. S., Braun-LaTour, K. A., \& Reichert, T. (2006). The impact of program context on motivational system activation and subsequent effects on processing a fear appeal message. Journal of Advertising, 35(3), 67-81.

Predebon, J. (1996). The relationship between the number of presented stimuli and prospective duration estimates: The effect of concurrent task activity. Psychonomic Bulletin \& Review, 3(3), 376-379.

Stern, R. M., Ray, W. J., \& Quigley, K. S. (2001). Psychophysiological recording (2nd ed.). New York: Oxford University Press.

Tassinary, L. G., \& Cacioppo, J. T. (2000). The skeletormotor system: Surface electromyography. In J. T. Cacioppo, L. G. Tassinary \& G. G. Berntson (Eds.), Handbook of psychophysiology (pp. 200-223). New York: Cambridge University Press.

Tse, P. U., Intriligator, J., Rivest, J., \& Cavanaugh, P. (2004). Attention and the subjective expansion of time. Perception and Psychophysics, 66(7), 1171-1189.

Webster, J. G., \& Phalen, P. F. (1997). The mass audience: Rediscovering the dominant model. Mahwah, NJ: Lawrence Erlbaum Associates. 
Copyright of Journal of Broadcasting \& Electronic Media is the property of Broadcast Education Association and its content may not be copied or emailed to multiple sites or posted to a listserv without the copyright holder's express written permission. However, users may print, download, or email articles for individual use. 